\title{
Females do not Express Learned Helplessness like Males do
}

\author{
Christina Dalla', Carol Edgecomb', Abigail S Whetstone' and Tracey J Shors*,' \\ 'Department of Psychology and Center for Collaborative Neuroscience, Rutgers University, Piscataway, NJ, USA
}

\begin{abstract}
Women are more likely than men to suffer from stress-related mental disorders, such as depression. In the present experiments, we identified sex differences in one of the most common animal models of depression, that of learned helplessness. Male and female rats were trained to escape a mild footshock each day for 7 days (controllable stress). Each rat was yoked to another rat that could not escape (uncontrollable stress), but was exposed to the same amount of shock. One day later, all stressed rats and unstressed controls were tested on a more difficult escape task in a different context. Most males exposed to uncontrollable stress did not learn to escape and were therefore helpless. In contrast, most females did learn to escape on the more difficult escape task, irrespective of whether they had been exposed to controllable or uncontrollable stress. The sex differences in helplessness behavior were not dependent on the presence of sex hormones in adulthood, because neither ovariectomy of females nor castration of males abolished them. The absence of helplessness in females was neither dependent on organizational effects of testosterone during the day of birth, because masculinized females did not express helplessness as adults. Thus, sex differences in helplessness behavior are independent of gonadal hormones in adulthood and testosterone exposure during perinatal development. Learned helplessness may not constitute a valid model for depressive behavior in women, at least as reflected by the response of female rats to operant conditioning procedures after stressful experience.

Neuropsychopharmacology (2008) 33, 1559-1569; doi: I0. I038/s.npp. I 301533; published online 22 August 2007
\end{abstract}

Keywords: learned helplessness; stress; sex differences; sex hormones; depression; development

\section{INTRODUCTION}

Women are more susceptible than men to stress-related psychiatric disorders, such as major depression, generalized anxiety disorder, acute and post-traumatic stress disorder (Holden, 2005; Kessler, 2003; Kessler et al, 1995; Kornstein, 1997; Nemeroff et al, 2006; Somers et al, 2006; Stein et al, 2002; Steiner et al, 2005). The reasons for these gender differences are not known, but it is possible that they emerge from different responses to stressful life events and different coping strategies (Kendler et al, 2001b; Klein and Corwin, 2002; Maciejewski et al, 2001; Nemeroff et al, 2006; Sherrill et al, 1997). Gender differences in these disorders are often attributed to the presence of different levels of sex hormones either during adulthood (ie activational effects) or during early development (ie organizational effects) (Altemus, 2006; Joffe and Cohen, 1998; Rubinow et al, 1998; Steiner et al, 2003). Genetic and social factors also contribute to sex differences in mental illness (Barr et al, 2004b; Breslau et al, 1997; Kendler, 1998; Kendler et al, 2001a; Meagher and Murray, 1997).

One way to evaluate the role of sex hormones in stressrelated illness is to model the disease in laboratory animals

*Correspondence: Professor TJ Shors, Department of Psychology and Center for Collaborative Neuroscience, Rutgers University, 152 Frelinghuysen Road, Piscataway, NJ 08854, USA, Tel: + I 732445 6968, Fax: + I 732445 2263, E-mail: shors@rutgers.edu

Received 22 March 2007; revised 4 July 2007; accepted I 8 July 2007
(Dalla et al, 2005; Drossopoulou et al, 2004; Maier, 1984; McCarthy and Konkle, 2005; Nestler et al, 2002; Palanza, 2001; Willner, 1995) and then manipulate the presence of sex hormones. The most common animal model of 'stress and coping' is that of 'learned helplessness' (Maier, 1984; Seligman and Beagley, 1975). With it, animals are exposed to either controllable or uncontrollable stressful events and later, they are tested on a new task in which all animals are given the opportunity to control the stressor, usually by escape. In most reports, animals that are exposed to uncontrollable stressful events do not learn to escape during testing on the new task (Overmier and Seligman, 1967; Seligman and Maier, 1967). This behavior has been equated with a sense of 'giving up', experienced by humans with major depression (Miller and Seligman, 1975). Thus, this model may have some predictive validity (Cryan et al, 2002; Willner, 1986) and as such, variations of it have been used extensively to study the neurobiology of depressive and anxiety disorders (Maier and Watkins, 2005). Interestingly enough, the vast majority of studies using this model have been conducted in males.

Two decades ago, it was reported that female rats do not express learned helplessness behavior to the same degree as do males (Heinsbroek et al, 1991; Kirk and Blampied, 1985; Steenbergen et al, 1990), but the reasons for its absence were not identified. We have recently verified the sex difference (Shors et al, 2007) and explored its hormonal basis in the present study. First, surgical ovariectomy 
(OVX) was used to determine whether the absence of helplessness in females was due to the presence of ovarian hormones (estrogen and progesterone). Second, castration was used to determine whether the presence of helplessness in males was dependent on the presence of testosterone in adulthood. Because neither manipulation prevented the sex differences in helplessness behavior, we investigated whether they emerged as a result of testosterone exposure during perinatal development of the brain (MacLusky and Naftolin, 1981). To our surprise, even masculinization of the female brain did not uncover helplessness behavior in females.

\section{MATERIALS AND METHODS}

\section{General Procedures}

Subjects. Experiments were approved by the Rutgers University Animal Care and Facilities Committee and are in compliance with the rules and regulations specified by the 'PHS policy on Humane Care and Use of Laboratory Animals' and the 'Guide for the Care and Use of Laboratory Animals'. Adult (2-3 months) male (300-350 g) and female (250-350 g) Sprague-Dawley rats were individually housed with ad libitum access to food and water and maintained on a 12-h light/dark cycle. Stages of estrus were determined in female rats with daily vaginal smears, as described (Hodes and Shors, 2005; Leuner and Shors, 2006).

General activity. All rats were tested in adulthood for general activity levels during the light phase and before stressful procedures. Each rat was placed individually in a Plexiglas activity chamber $\left(30 \mathrm{~cm}^{3}\right)$ for $30 \mathrm{~min}$. Activity in the chamber was monitored with eight photobeams at $4 \mathrm{~cm}$ intervals (Omnitec Electronics Inc., NS, Canada). Breaks in the beams were converted to horizontal (walking) and vertical (rearing) movements.

Learned helplessness model. Rats were yoked in pairs (of the same sex and condition) and placed in one of two electrically linked shuttle-boxes (Med Associates Inc., St Albans, Vermont, USA). Each shuttle-box $\left(46 \times 18 \times 19 \mathrm{~cm}^{3}\right)$ was located within a sound attenuated illuminated (15 W) chamber $\left(69 \times 69 \times 63 \mathrm{~cm}^{3}\right)$. A scrambled shock generator delivered $1 \mathrm{~mA}$ electric pulse through the grid floor and walls of the apparatus. Each shuttle-box consisted of grid flooring, steel walls, a Plexiglas top, and a doorway in the center. During training with a fixed-ratio 1 (FR1) task, one rat could escape a $1 \mathrm{~mA}$ footshock (controllable stress) by passing through the doorway once and tripping a balance switch, which terminated the shock in both shuttle-boxes simultaneously. At the same time, the yoked rat could traverse the apparatus, but could not terminate the shock (uncontrollable stress). Therefore, the yoked rat was exposed to the same amount and duration of shock as the rat that could escape (Shors et al, 1989, 2007) (Figure 1). Rats were trained for 7 consecutive days, each day for 30 trials with a maximum latency to escape of $30 \mathrm{~s}$ and an intertrial interval of $60 \mathrm{~s}$. Latency to escape in the FR1 task was used as a measure of performance in rats exposed to controllable stress.

On the eighth day, all rats were tested individually on a fixed-ratio 2 (FR2) task, in which escape was possible for all subjects, but required passing through the doorway twice in order to turn off the shock (Figure 1). The context for testing was altered in the following ways: black and white stripes lined the walls of the chamber, an odor of menthol was placed in each chamber, and white bulbs were replaced with red bulbs. Latency to escape the FR2 was measured over 30 trials of training with a maximum latency of shock of $10 \mathrm{~s}$ and an intertrial interval of $60 \mathrm{~s}$. Groups of animals were considered to express learned helplessness behavior in the FR2 task, when they exhibited high escape latencies (in average more than $8 \mathrm{~s}$ ) that were not decreased after repeated testing (across 30 trials). In order to investigate differences between groups, we calculated the percentage of helpless rats in each group that was previously exposed to uncontrollable stress. Rats that failed to escape more than 10 trials in the last 15 trials of the FR2 test were considered as helpless. This was considered informative, because individual differences in the learned helplessness paradigm have been reported (Drugan et al, 1997; Setnik et al, 2004; Vollmayr and Henn, 2001).

Additional groups of rats that had not been previously exposed to any footshock were also tested in the FR2 task (unstressed groups). Thus, as shown in Figure 1, each experiment included three groups per hormonal condition/ manipulation: The Controllable stress group consisted of animals exposed for 7 consecutive days to escapable stress (FR1 training) and then on the eighth day tested on the FR2 test, the Uncontrollable stress group consisted of animals exposed for 7 consecutive days to non-escapable stress (yoked to animals from Controllable stress group exposed to FR1 training) and then on the eighth day tested on the FR2 test and the Unstressed group consisted of animals left undisturbed in their home cages and only tested on the FR2 test.

Experiment 1: testing of gonadectomized males and females. Rats were anesthetized with Pentobarbital $(25 \mathrm{mg} /$ $\mathrm{kg}$ ) and through inhalation of isoflurane and oxygen. Females were subjected to a bilateral OVX $(n=18)$ or sham-operation $(n=12)$. Males were subjected to a castration (orchidectomy) $(n=26)$ or sham-operation $(n=18)$. All rats were tested 1 week after surgeries for general activity (explained in detail above). Two days later, rats of the same sex and hormonal condition were yoked in pairs, stressed (Controllable or Uncontrollable stress groups) for 7 days in the FR1 task and tested 1 day later for learned helplessness behavior in the FR2 test (explained in detail above). Sham-operated females were yoked together according to stage of the estrous cycle, as previously described (Shors et al, 2007). On the first day of FR1 training, three pairs of the sham-operated females were in estrus: two in diestrus 2 and one in proestrus.

Groups of castrated male $(n=9)$ and OVX female $(n=8)$ rats and groups of sham-operated male $(n=7)$ and female $(n=8)$ unstressed controls (Unstressed groups) were also tested for learned helplessness behavior in the FR2 test (Figure 1). On the day of FR2 testing, two of the shamoperated unstressed females were in each stage of the estrous cycle (proestrus, estrus, diestrus 1, and diestrus 2).

Experiment 2: testing of masculinized females. Within $24 \mathrm{~h}$ of birth, female pups $(n=18)$ were injected once in the afternoon subcutaneously with $0.02 \mathrm{ml}$, total of $125 \mu \mathrm{g}$, of testosterone propionate (TP; Sigma-Aldrich Inc.) dissolved 

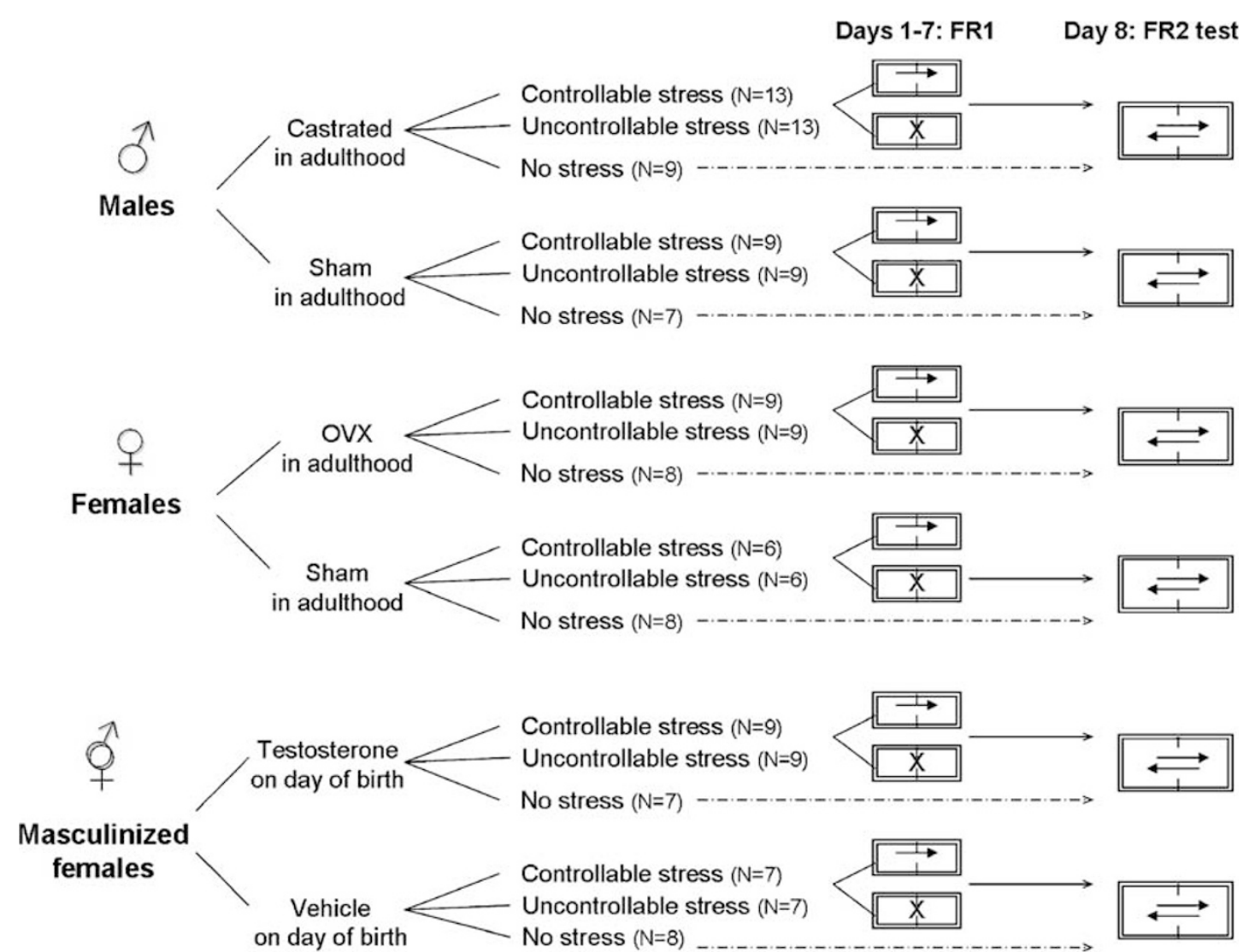

Figure I Experimental Design, in experiment I, male and female rats were gonadectomized or sham-operated in adulthood. One week later, they were divided into three groups per sex/hormonal condition: the Controllable stress group, the Uncontrollable stress group, and the No stress group. In experiment 2, female pups were injected with testosterone at birth or with vehicle. In adulthood, they were also divided into the same three groups per treatment. Rats in stress groups were exposed for 7 consecutive days to FRI training. One rat was placed in the first shuttle-box, in which it could escape the footshock (I mA) by passing through the doorway once (fixed-ratio I, (FRI)) and tripping a balance switch (controllable stress). The yoked rat was placed in the other shuttlebox and could not escape the footshock, even when it was passing through the doorway (uncontrollable stress). When the rat in the first shuttle-box terminated the shock, the shock was also terminated for the rat in the other shuttle-box. Rats were stressed in this way for 7 consecutive days, each day for 30 trials. Latency to escape in the FRI task was used as a measure of performance in rats exposed to controllable stress. On the eighth day, all rats were tested individually on the fixed-ratio 2 (FR2) test. A rat was placed in the shuttle-box (in a different context), in which it could escape the footshock (I mA) by passing through the doorway twice (FR2) and tripping a balance switch. Latency to escape in the FR2 test was measured over 30 trials (maximum shock duration: 10s).

in sesame seed oil $(6.25 \mathrm{mg} / \mathrm{ml})$. Females from different litters were injected with $0.02 \mathrm{ml}$ of sesame oil alone $(n=14)$. This treatment has been used frequently to study the organizational effects of androgens on the brain and has been shown effective for masculinizing the female brain and many aspects of behavior (Barraclough and Gorski, 1961; Beatty and Beatty, 1970; Shors and Miesegeas, 2002).

Successful TP-treatments and masculinization of female rats was verified in adulthood by inspection of the vagina and vaginal smears. In masculinized females, there was no vaginal canalization and vaginal smears, as it happens normally in females during puberty around the postnatal day 35 (Hodes and Shors, 2005). One TP-treated female that exhibited normal vaginal canalization during puberty was excluded from the study.

All females were tested in adulthood for general activity ( 2 months old). Two days later, females were yoked in pairs, stressed (Controllable and Uncontrollable stress groups) for 7 days in the FR1 task and tested 1 day later for learned helplessness behavior in the FR2 test (explained in detail above). Vehicle-treated females were yoked together according to the stage of the estrous cycle. On the first day of FR1 training, three pairs from the vehicle-treated females were in estrus, two pairs were in diestrus 1 , and two pairs were in diestrus 2. Groups of TP-treated females $(n=7)$ and vehicle-treated $(n=8)$ female unstressed controls (Unstressed group) were also tested for learned helplessness behavior in the FR2 test. On the day of FR2 testing, one vehicle-treated unstressed female was in estrus, three in proestrus, one in diestrus 1 , and two in diestrus 2 .

Statistics. For experiment 1, behavioral data from general activity measurements were analyzed by using two-way analysis of variance (ANOVA) with sex (male $v s$ female) and surgery (gonadectomy $v s$ sham-operation) as between factors. Performance during training in FR1 and FR2 tests was analyzed with repeated ANOVA (across seven sessions for FR1 or blocks of five trials for FR2), with two or three between-subjects factors: sex (males vs females), surgery (gonadectomy $v s$ sham-operation), and condition (controllable stress, uncontrollable stress, and unstressed controls for FR2 escape latencies). For experiment 2, activity levels 
were analyzed with ANOVA with treatment (testosterone $v s$ vehicle) as the between subjects factor. Performance during training in FR1 and FR2 tasks was analyzed with repeated measures ANOVA (across seven sessions for FR1 or blocks of five trials for FR2), with one or two between-subjects factors: treatment (testosterone vs vehicle) and condition (controllable stress, uncontrollable stress, and unstressed controls for FR2 escape latencies). Post hoc pairwise comparisons were conducted on significant interactions for condition and Newman-Keuls method was implemented to control for family-wise error rate. Separate one-way ANOVAs were performed to evaluate specific differences between groups. Probabilities of less than 0.05 were considered statistically significant.

\section{RESULTS}

\section{Experiment 1}

Effects of sex and gonadectomy on general motor activity and FR1 escape performance. Vertical but not horizontal movements were reduced in the gonadectomized rats $(\mathrm{F}(1,52)=5.00 ; p<0.05) \quad($ Table 1$)$. Escape performance during training on the FR1 task was unaffected by gonadectomy (Figure $2 \mathrm{a}$ and $\mathrm{c}$ ). As such, males and females that were exposed to a sham surgery as well as those that were castrated or OVX readily learned to escape and decreased their escape latencies across days of FR1 training $(\mathrm{F}(6,72)=51.9 ; \quad p<0.001, \quad \mathrm{~F}(6,48)=5.71 ; p<0.005$ for castrated and sham males, respectively) (Figure $2 \mathrm{a}$ ) and $(\mathrm{F}(6,48)=5.09 ; p<0.001, \mathrm{~F}(6,30)=4.62 ; p<0.005$, for OVX and sham females, respectively) (Figure $2 \mathrm{c}$ ). However, there was an interaction among the factors of sex, hormonal condition, and days of FR1 training $(F(6,198)=2.6$; $p<0.05)$. On the first day of training on the FR1 task, sham-operated females learned to escape sooner than did sham-operated males. This sex difference during very early training was not expressed in animals without gonads (Figure $2 \mathrm{a}$ and $\mathrm{c}$ ).

Males express helplessness, even after castration. With respect to the expression of helplessness, analysis indicated

Table I General Motor Activity Levels

\begin{tabular}{llcc}
\hline Sex & Condition & Horizontal activity & Vertical activity \\
\hline Male & Sham & $1600 \pm 127$ & $190 \pm 28$ \\
& Castrated & $1546 \pm 82$ & $145 \pm 14 *$ \\
Female & Sham & $1690 \pm 184$ & $233 \pm 31$ \\
& OVX & $1790 \pm 129$ & $171 \pm 24 *$ \\
Female & Vehicle & $2507 \pm 122$ & $330 \pm 94$ \\
& Testosterone & $1990 \pm 94 * *$ & $227 \pm 29 *$ \\
\hline
\end{tabular}

Abbreviation: OVX, ovariectomized.

Male and female rats were gonadectomized in adulthood or sham-operated and tested I week later. Female pups were injected with testosterone (masculinized females) or vehicle and tested in adulthood. Gross motor activity was measured before the beginning of any stressful procedures. In experiment I, vertical activity was reduced in gonadectomized rats in comparison to their controls (sham-operated rats). In experiment 2, activity levels were lower in testosterone-treated females, in comparison to their vehicle-treated controls. * $p<0.05$, *** $p<0.01$. that neither males with a sham surgery nor those that were castrated and exposed to uncontrollable stress were able to learn to escape during training on the FR2 task $(\mathrm{F}(5,40)=2.25 ; p>0.05 ; \mathrm{F}(5,60)=2.29 ; p>0.05$, respectively). There was no interaction between castration and trials of training on the FR2 task $(p>0.05)$ (Figures $2 \mathrm{~b}$ and $5 a)$. According to the criterion, $66 \%$ of the males that were previously exposed to uncontrollable stress were helpless, whereas $54 \%$ of the castrated males were helpless (Figure $5 \mathrm{~b}$ ). These numbers are similar to those previously reported for Sprague-Dawley male rats (Drugan et al, 1997). As expected, previous training with controllable stress on the FR1 task reduced the time it took for males to learn the FR2 task $(\mathrm{F}(1,40)=62.3 ; p<0.001)$. Males previously exposed to controllable stress were faster to escape during training on the FR2 task than males exposed to uncontrollable stress $(p<0.05)$ (Figure $2 b)$. Castration did affect the behavior of males that were previously exposed to controllable stress $(\mathrm{F}(1,20)=4.82 ; p<0.05)$; sham-operated males exposed to controllable stress took longer to learn (ie higher escape latencies) than the respective castrated males (Figure 2b). Castration also affected escape behavior specifically during training across trials of FR2 testing $(\mathrm{F}(5,70)=2.73 ; p<0.05)$. Males that were not stressed and sham-operated did not learn and in fact increased their latency to escape across FR2 trials $(\mathrm{F}(5,30)=3.18 ; p<0.05)$ (Figure 3a). In contrast, castrated males that were not stressed learned to escape and thus decreased their escape latencies across FR2 trials $(\mathrm{F}(5,40)=4.85 ; p<0.01)$ (Figure 3a).

Females do not express learned helplessness behavior, even after ovariectomy. In contrast with males, females that had been exposed to uncontrollable stress during training on the FR1 task did learn to escape during training on the FR2 task, irrespective of whether they were OVX or not $(\mathrm{F}(5,40)=7.05 ; p<0.001, \mathrm{~F}(5,25)=9.48 ; p<0.001$ for $\mathrm{OVX}$ and sham females exposed to uncontrollable stress, respectively) (Figures $2 \mathrm{~d}$ and $5 \mathrm{a}$ ). In general, females that were exposed to the uncontrollable stress learned to escape faster than males during testing on the FR2 task (overall sex effect: $\mathrm{F}(1,33)=7.02 ; p<0.05$ and interaction between sex and trials of testing $\mathrm{F}(5,165)=7.88 ; p<0.001)$. Less than $20 \%$ of the females expressed helplessness behavior; similarly, $22 \%$ of OVX females were helpless (Figure 5b).

Females that were not stressed readily learned to escape during training for the first time on the FR2 task, irrespective of whether they were OVX or not $(\mathrm{F}(5,35)=4.76 ; p<0.01, \mathrm{~F}(5,35)=3.29 ; p<0.05$ for $\mathrm{OVX}$ and sham unstressed females, respectively) (Figure $3 \mathrm{~b}$ ). Again, unstressed females learned to escape faster during training on the FR2 task when compared to males (overall sex effect: $F(1,28)=29.67 ; p<0.001$ and interaction between sex and trials of testing $\mathrm{F}(5,140)=2.63 ; p<0.05)$ (Figure $3 \mathrm{a}$ and $\mathrm{b}$ ).

The performance of females that had learned to escape during FR1 training (controllable stress) was different from that in all other groups of females $(p<0.05)$. Their latencies did not change across trials of training, because they had already learned to escape early during training (a floor effect). There was no effect of OVX on performance of the 


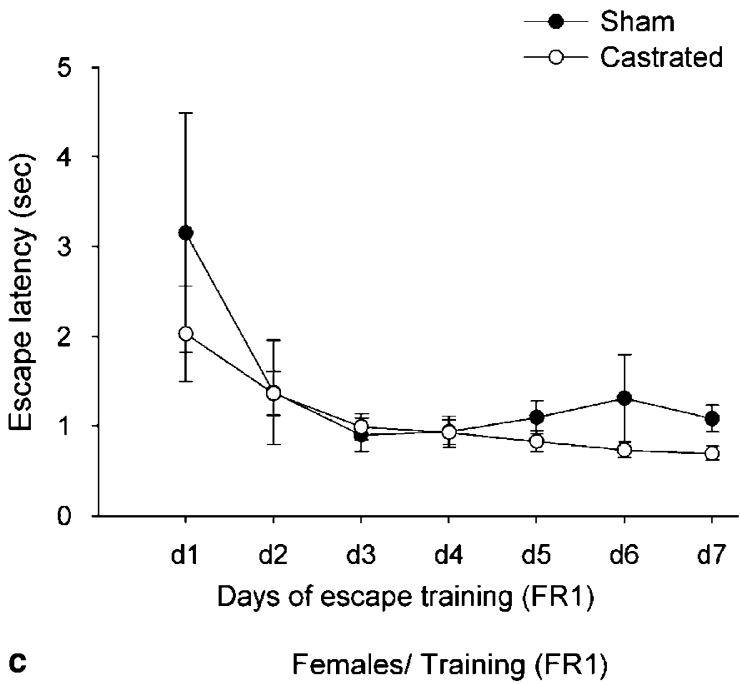

c

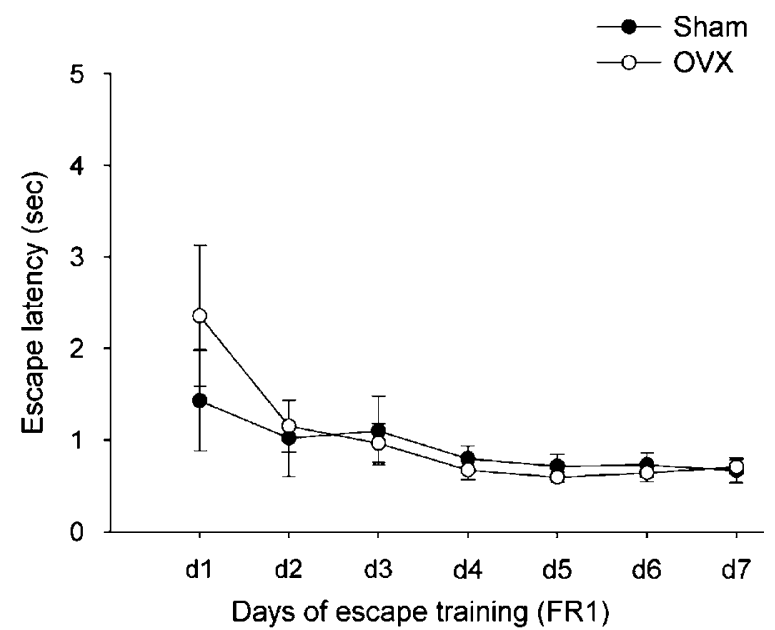

b

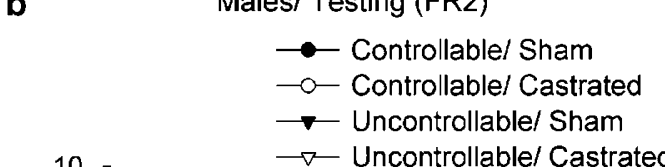

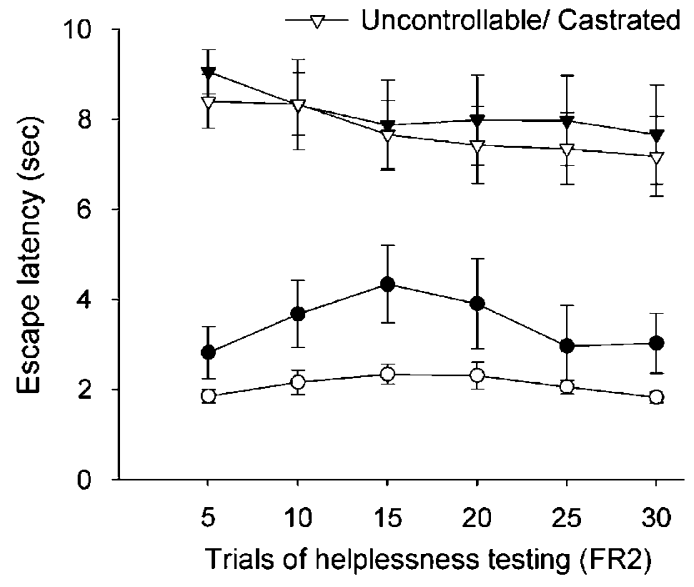

d

Females/ Testing (FR2)
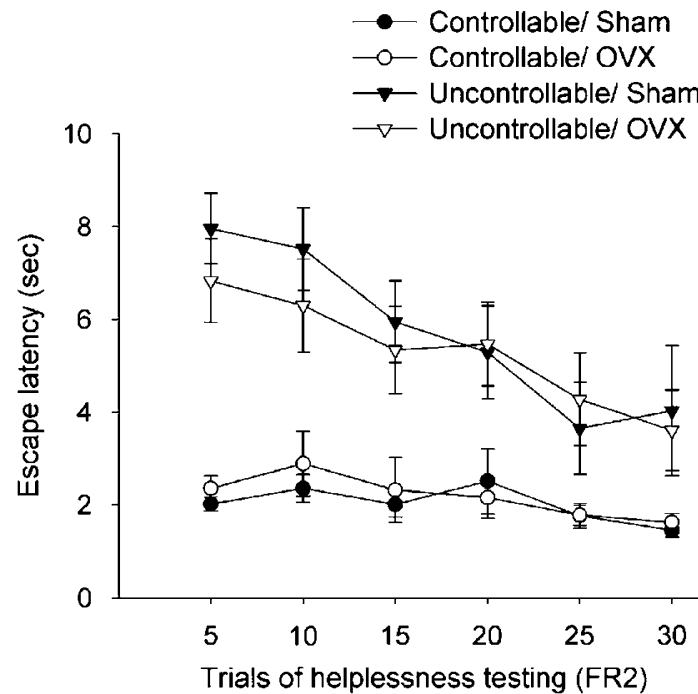

Figure 2 Males expressed learned helplessness behavior whereas females did not. (a) During training on a fixed-ratio I (FRI) task, rats had to cross the shuttle-box once to escape the footshock (Controllable stress groups). The escape latencies of male sham-operated and castrated rats were decreased $(p<0.00$ I and $p<0.005$, respectively) during 7 days of FRI training (means of 30 trials \pm SEM). (b) During testing on a fixed-ratio 2 (FR2) task, rats had to cross the shuttle-box twice to escape the footshock. The graph depicts the escape latencies during testing on the FR2 task (means of five trials \pm SEM) in the animals that were trained on the FRI task in (a) (controllable stress), along with their yoked animals (uncontrollable stress). Male sham-operated and castrated rats from the uncontrollable stress groups, did not learn to escape during testing on the FR2 task ( $p>0.05)$. Male castrated rats from the controllable stress group exhibited higher escape latencies in the FR2 test than their respective sham-operated males $(p<0.05)$. (c) Similar data are presented for sham-operated and ovariectomized (OVX) female rats. The escape latencies of female sham-operated and OVX rats (Controllable stress groups) were decreased $(p<0.005$ and $p<0.00$ I, respectively) during 7 days of FRI training (means of 30 trials \pm SEM). (d) Female sham-operated and OVX rats from the Uncontrollable stress groups exhibited high escape latencies during the first trials of the FR2 task, but readily learned to escape $(p<0.00 \mathrm{I})$ during further testing (means of five trials $\underline{ \pm}$ SEM).

FR2 task and no interaction among the factors related to OVX, stress condition, and trials of training. Escape latencies in sham-operated females did not vary as a function of stage of estrus $(p>0.05)$, but the numbers were too few to draw meaningful conclusions about the effects of estrous cycle on operant conditioning.

\section{Experiment 2}

Masculinized females were less active, but still did not express helplessness. Females that were treated with testosterone at birth moved less as adults than did those injected with the same volume of vehicle. The decrease was evident in measures of horizontal and vertical movements $(\mathrm{F}(1,32)=10.87 ; p<0.001 ; \mathrm{F}(1,32)=4.08 ; p<0.05$, respectively) (Table 1). However, when trained with operant conditioning, they did not differ from females treated with vehicle $(p>0.05)$. Both groups of females readily learned to escape during FR1 training, with shorter escape latencies across days $(\mathrm{F}(6,48)=8.16 ; \quad p<0.001, \quad \mathrm{~F}(6,36)=2.29$; $p<0.05$ for TP and vehicle-treated females, respectively) (Figure 4a). 
Treatment with testosterone at birth did not interact with the stressor manipulation (controllable, uncontrollable, and unstressed) or trials of testing on the FR2 task $(p>0.05)$. Both testosterone and vehicle-treated unstressed females learned to escape during testing for the first time on the FR2 task $(\mathrm{F}(5,35)=4.64 ; p<0.005, \mathrm{~F}(5,30)=7.41 ; p<0.05$, respectively) (Figure $3 \mathrm{c}$ ).

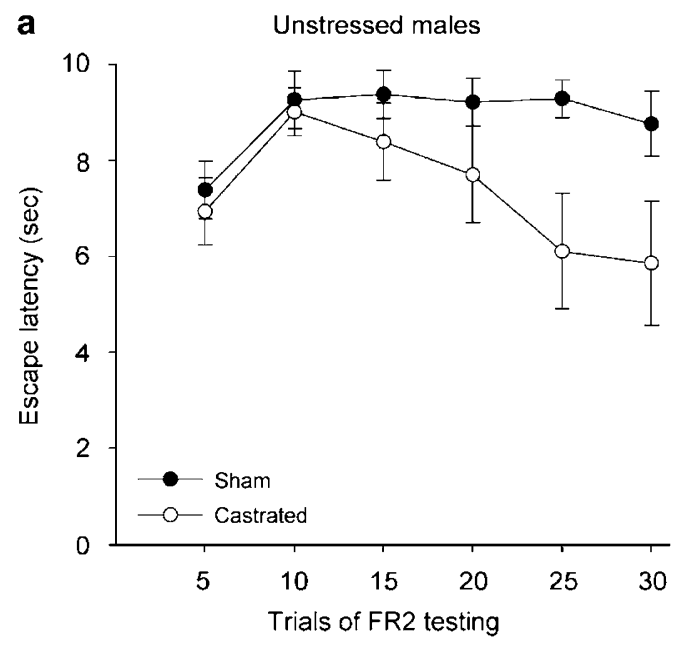

b Unstressed females

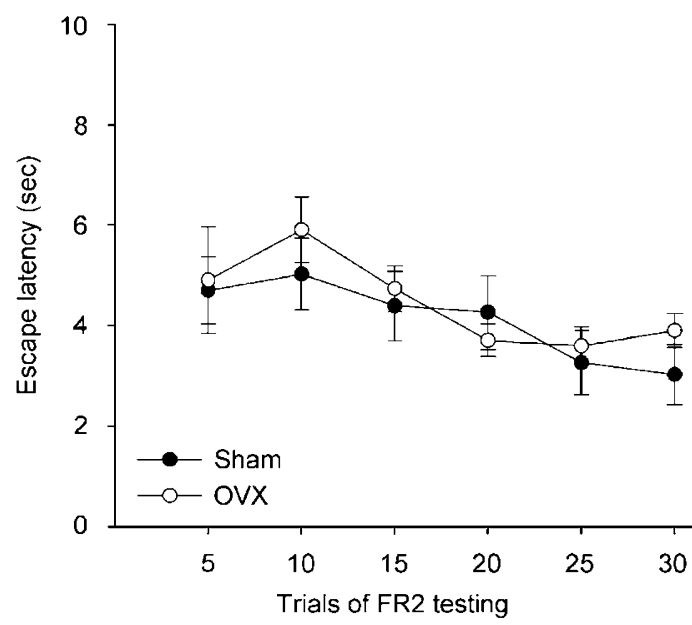

C Unstressed masculinized females

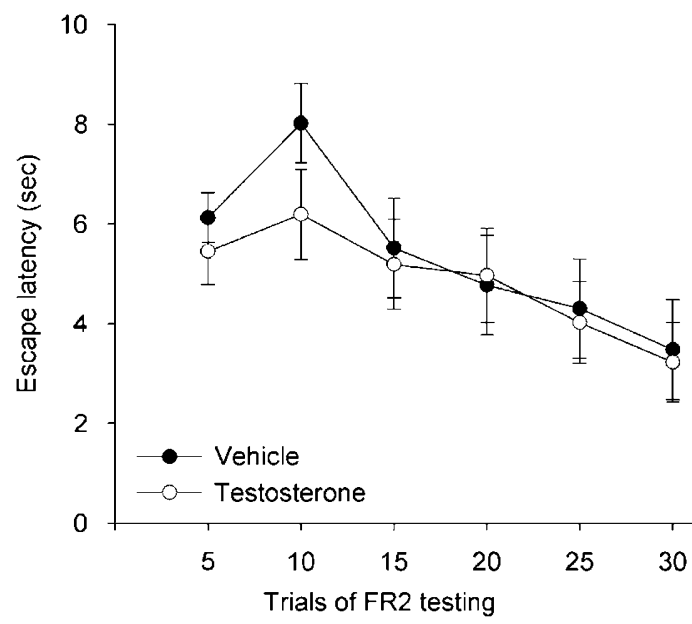

Also, performance in females that were treated with testosterone or vehicle was similar after exposure to uncontrollable stress; they learned to escape during testing on the FR2 task after being exposed to uncontrollable stress $(\mathrm{F}(5,40)=5.34 ; p<0.01, \mathrm{~F}(5,30)=3.04 ; p<0.05$ for TP and vehicle-treated females exposed to uncontrollable stress, respectively) (Figures $4 \mathrm{~b}$ and $5 \mathrm{a}$ ). Specifically, there was no effect of testosterone treatment $(\mathrm{F}(1,13)=1.156 ; p=0.3)$, nor interaction between trials and testosterone treatment $(\mathrm{F}(1,13)=0.25 ; p=0.6)$ during training on the FR2 task for rats that had been exposed to uncontrollable stress. Using the same criterion as in experiment 1, fewer than $15 \%$ of females treated with vehicle expressed helplessness, with comparable numbers in females treated with testosterone (Figure 5b).

Escape performance in females that had learned to escape during FR1 training (controllable stress) differed from the performance of all other groups of females $(p<0.05)$. Their latencies did not decrease during testing on the FR2 task (Figure 4b), presumably because they performed so well during the early trials of FR2 testing (a floor effect). Escape latencies were not influenced by stages of estrus $(p>0.05)$, although total numbers in each group were few.

\section{DISCUSSION}

Together, these data demonstrate robust sex differences in the expression of helplessness behavior, which are independent of activational effects of reproductive hormones and organizational effects of testosterone during perinatal development. Specifically, most male rats that were exposed to uncontrollable stress did not learn to escape during training on a more difficult escape task in a different context; ie, they expressed learned helplessness behavior. In contrast, the majority of females did not express learned helplessness behavior after exposure to the same stressor. Importantly, females that had been exposed to the uncontrollable stress eventually performed similarly to females that were not stressed or exposed to controllable stress, whereas most males did not learn with further training. In fact, even males that were not previously stressed did not learn to escape. Only males that had learned to control the stressor readily learned to escape, ie they responded similarly to females that were stressed or not stressed. Surprisingly, the removal of the gonads in males and females did not abolish sex differences in helplessness. Moreover, masculinization of the female brain during early development did not uncover helplessness in adult females. Thus, it appears that the sex differences in

Figure 3 Castration increased operant conditioning in males, but ovariectomy and masculinization of the female brain were inconsequential. Graphs depict the escape behavior in rats that were not exposed to any stressor before testing on the fixed-ratio (FR2) task. (a) Sham-operated males increased their escape latencies $(p<0.05)$ during FR2 testing (means of five trials \pm SEM), while castrated males decreased them $(p<0.05)$. (b) Ovariectomized (OVX) females and their sham-operated controls decreased their escape latencies $(p<0.05)$ during FR2 testing (means of five trials $\pm S E M)$. (c) Testosterone-treated females (masculinized at birth) and their vehicle-treated controls decreased their escape latencies $(p<0.005$ and $p<0.05$, respectively) during FR2 testing in adulthood (means of five trials \pm SEM). 
a

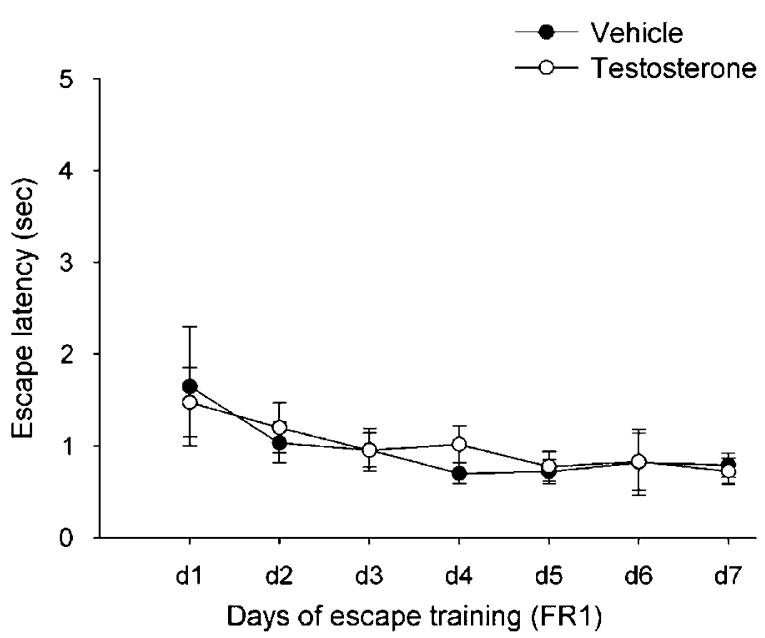

b

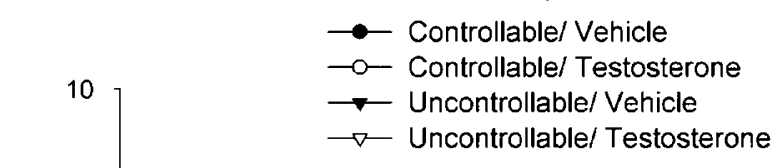

$\rightarrow$ Controllable/ Vehicle

$\rightarrow$ Uncontrollable/ Vehicle

$\neg$ Uncontrollable/ Testosterone

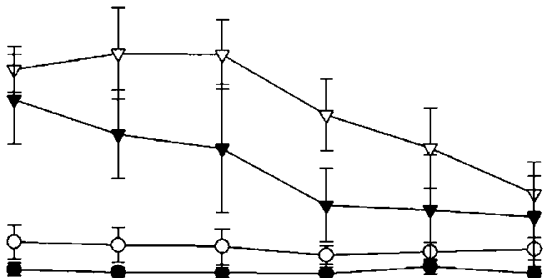

0

Figure 4 Masculinized females did not express helplessness behavior. (a) The escape latencies of testosterone-treated females (masculinized at birth) and vehicle-treated controls (Controllable stress groups) decreased ( $p<0.001$ and $p<0.05$, respectively) during 7 days of fixed-ratio (FRI) training (means of 30 trials \pm SEM). (b) Female testosterone and vehicle-treated rats from the Uncontrollable stress groups, exhibited high escape latencies during the first trials of the fixed ratio (FR2) task, but learned to escape $(p<0.01$ and $p<0.05$, respectively) during further testing (means of five trials \pm SEM).

helplessness behavior are not mediated by the presence or influence of sex hormones, at least to the extent that they were studied here.

Even though females did learn to escape after exposure to uncontrollable stress, this effect may be limited to tests of operant conditioning. During training with other types of conditioning procedures, performance in females is actually quite susceptible to the negative consequences of uncontrollable stressful experience (Shors, 2006; Wood and Shors, 1998). For example, with classical eyeblink conditioning procedures, female rats express a severe deficit in learning after exposure to the same regimen of repeated uncontrollable stress as used here (Leuner et al, 2004). The reasons for the different responses probably reflect the inherent differences between operant and classical conditioning and the requisite responses. During operant conditioning, the animal must emit a voluntary motor response in order to change the outcome and learn, whereas animal emits an obligatory unconditioned response to the unconditioned stimulus during classical conditioning, irrespective of volition. Thus, the two types of training procedures are vastly different in terms of their dependence on volitional activity and the learning processes involved (Shors, 1998). That said, the sex differences described here were not explained by measurable differences in gross motor activity, because baseline movements did not differ between males and females. Moreover, females that were treated with testosterone at birth were less active as adults than vehicle-treated females, yet they still did not express helplessness. It is noted that numerous studies report sex differences in gross motor activity (Alonso et al, 1991; Johnston and File, 1991; Palanza, 2001). It is possible that in the present study, the housing conditions or the method of assessment may contribute to the absence of a sex difference in 'moving duration', as reported (Dalla et al, 2005). Irrespective, sex differences in operant responding presented here are not directly a result of sex differences in activity, as previously considered (Shors, 1998).
The sex differences in learned helplessness behavior reported here are likely affected by the fact that females learn to escape the shock much sooner than do males, even without any previous exposure to uncontrollable stress (unstressed animals, Figure 3), as reported for avoidance tasks (Beatty and Beatty, 1970; Heinsbroek et al, 1988, 1991; Scouten et al, 1975; Steenbergen et al, 1990; van Haaren and van de Poll, 1984a,b). Thus, when females are confronted with the FR2 demands, they overcome the tendency to avoid the side of the box where they just got shocked. In contrast, most males failed to re-enter the side in which they were shocked and thus accrued longer latencies. Even the males that did not previously experience any uncontrollable stress did not re-enter the side in which the shock occurred. The difference in response tendency between males and females is notable in that neither is necessarily 'better'; they are just different and likely mediated by non-associative processes related to punishment, electrical resistance, nociception, and/or analgesia (Aloisi and Bonifazi, 2006; Beatty and Beatty, 1970; Beatty and Fessler, 1977; Levine and Broadhurst, 1963; Romero et al, 1987, 1988; Shors, 1998; van Haaren and van de Poll, 1984a; Van Oyen et al, 1979; Vendruscolo et al, 2004). For example, females often respond actively to aversive stimulation, whereas males do so passively with freezing (Beatty and Beatty, 1970; Heinsbroek et al, 1991; Kirk and Blampied, 1985; Steenbergen et al, 1990). Females also express less conditional freezing than males during contextual fear conditioning (Gupta et al, 2001; Maren et al, 1994).

It is perhaps futile to try to identify one or even a few characteristics that can explain sex differences in this behavior. This point is exemplified in a recent study with stress and neurogenesis (Shors et al, 2007). Using the same procedures as here, we found that exposure to uncontrollable stress reduced cell proliferation in the male hippocampus more than did exposure to controllable stress. Its modulation by controllability, evident in males, was not evident in females. However, it cannot be concluded 

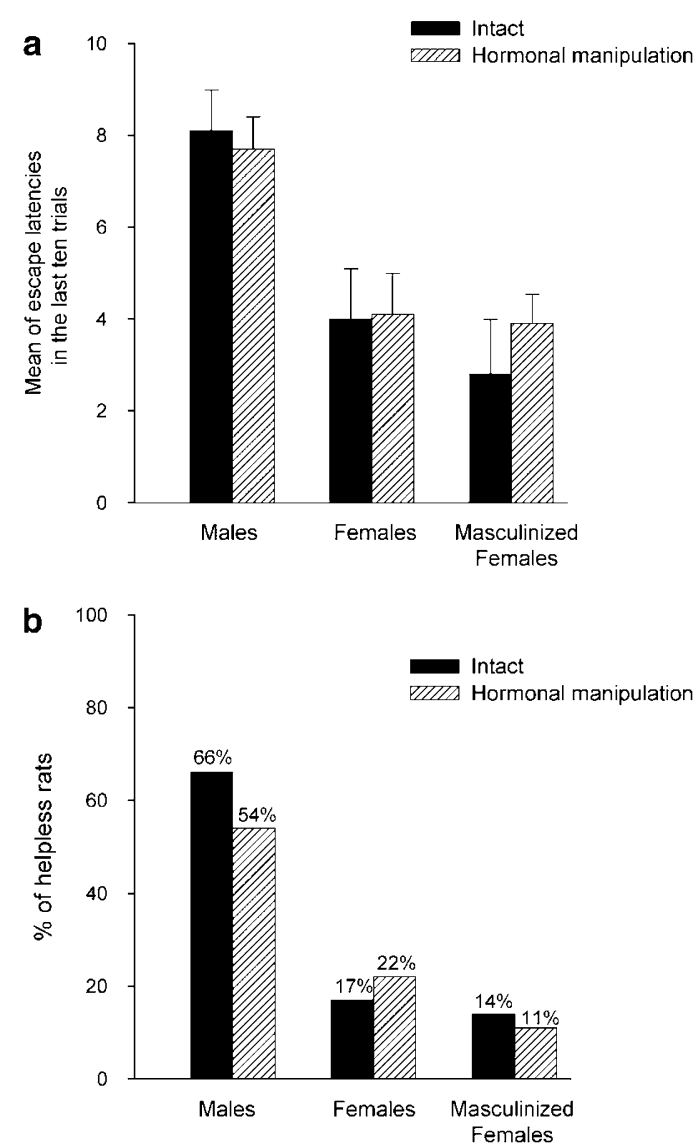

Figure 5 Fewer females than males expressed helplessness behavior: hormonal manipulation had no effect. (a) The graph depicts the mean escape latencies in the last 10 trials for each group exposed to uncontrollable stress during experiments 1 and 2 (escape latencies depicted in Figures 2b, d and 4b). Female rats exhibited shorter escape latencies than males during FR2 testing $(p<0.05)$, while ovariectomy, castration, and testosterone treatment had no effect $(p>0.05)$. (b) The graph depicts the percentage of helpless rats from each group exposed to uncontrollable stress during experiments $\mid$ and 2 . A rat was considered helpless when failed to escape more than 10 trials in the last 15 trials of the FR2 test.

necessarily that the newly generated cells themselves respond differently in males than in females; rather it is more likely that the behavioral or internal response to the external events are processed differently by males than females and this difference alters proliferation in one sex and not the other. Overall, the present data suggest that the effects of stress on learning in males $v s$ females are influenced by distinctive responses to environmental stimuli, a situation that is perhaps epitomized by training procedures associated with learned helplessness (Shors, 2006).

Sex differences in helplessness persisted in the absence of the major sources of sex hormones (gonads) in adulthood, since castration and OVX did not alter performance after exposure to uncontrollable stress. However, performance was different in the castrated males in some cases: their latencies to escape were shorter during testing on the FR2 task, in comparison to those that were either not stressed or exposed to controllable stress. These findings suggest that the presence of testosterone may modulate operant responding. Others have observed a modulatory effect of

testosterone on passive avoidance (van Oyen et al, 1980) as well as indices of 'emotional' behavior (Toufexis et al, 2005,2006 ), although there are reports for no effect on active avoidance (Beatty and Beatty, 1970; Scouten et al, 1975). Nevertheless, the present findings dissociate the role of testosterone in learned helplessness behavior that appears as a consequence of exposure to repeated uncontrollable stress, from its role in escape/avoidance behavior. Similarly, estrogen and progesterone can influence conditioned avoidance behavior in females (Diaz-Veliz et al, 1989; Sfikakis et al, 1978), but apparently not the expression of helplessness after exposure to uncontrollable stress. With respect to the cycle, Jenkins et al (2001) reported that females in diestrus 2 were more helpless than females in estrus. They took longer to escape during training on the FR1 and FR2 tasks when compared to females that were not stressed (Jenkins et al, 2001). However, other investigators have reported no change in similar behaviors across the estrous cycle (Setnik et al, 2004). In the present study, OVX females readily learned to escape during testing on the FR2 task even after exposure to uncontrollable stress. Thus, changes in hormone levels across the estrous cycle do not explain the sex differences in helplessness behavior presented here.

Many sex differences in adult behaviors can be reversed or at least minimized by manipulation of sex steroids during development (Barraclough and Gorski, 1961; Beatty and Beatty, 1970; Shors and Miesegeas, 2002; Williams et al, 1990). Testosterone treatment of females at birth alters the phenotype of the hypothalamic-pituitary-adrenal axis (Seale et al, 2005), the morphology of sexually dimorphic brain regions (Han and De Vries, 2003; MacLusky et al, 1987; Morris et al, 2004; Roselli and Klosterman, 1998) and affects certain aspects of learning (Roof, 1993; Roof and Havens, 1992; Shors and Miesegeas, 2002; Williams and Meck, 1991). Therefore, we were surprised that learned helplessness behavior did not emerge in females that were masculinized at birth. In a previous study, masculinization of the female brain reversed the effects of uncontrollable stress on classical conditioning (Shors and Miesegeas, 2002). Instead of reducing classical eyeblink conditioning, exposure to the stressful event facilitated learning in females; they responded like intact males do. It is curious that the effects of stress on learning would be organized by testosterone, while learning one task and not another. Perhaps, specific brain regions are critical for one and not the other training regimen. In the case of classical conditioning, the hippocampus is necessary for the effects of stress on learning in both males and females (Bangasser and Shors, 2007), but the bed nucleus of the stria terminalis is only necessary in males (Bangasser et al, 2005). If these same brain regions are not critically involved in the expression of learned helplessness behavior, their organization during this period of development may not then influence the expression of sex differences in adulthood. It remains possible that sex hormones organize sex differences in learned helplessness during other periods of brain development, such as during prenatal development or puberty (Arnold and Breedlove, 1985; Sisk and Zehr, 2005). At the same time, de novo synthesized estrogen in the female hippocampus during early development could influence these behaviors in adulthood (McCarthy and Konkle, 2005). 
The present results suggest that testosterone and its metabolites (estrogen and non-aromatizable androgens), derived from peripheral sources, do not influence learned helplessness behavior through organizational effects during the critical period of the perinatal brain development (MacLusky and Naftolin, 1981). Thus, it is possible that expression of learned helplessness behavior is modulated by factors other than hormonal ones. Genetic background has been reported to play a role in learned helplessness behavior in mice (Caldarone et al, 2000) and genes regulate aspects of sexual differentiation of the brain (Arnold, 2004; Davies and Wilkinson, 2006). There is growing literature implicating genetic and epigenetic factors in the etiology of depression, especially as they relate to sex differences in serotonin and its transporters (Barr et al, 2004a,b; Sjoberg et al, 2006; Weiss et al, 2005). As with many mental illnesses, these inherited characteristics presumably interact with developmental experience and stressful life experiences to achieve a threshold for the expression of abnormal behavior. The present results question the construct validity of learned helplessness to model depression in women, at least in the form it was used in the present study. They also underscore the need to develop animal models for affective disorders that are experienced by women.

\section{ACKNOWLEDGEMENTS}

This work was supported by National Institutes of Health (National Institute of Mental Health 59970) and National Science Foundation (Integrative Organismal Systems 0444364) to Dr Tracey J Shors. This research was supported by a Marie Curie International Fellowship to Dr Christina Dalla, within the sixth European Community Framework Programme.

\section{DISCLOSURE/CONFLICT OF INTEREST}

There is no conflict of interest for the present work.

Over the past 3 years the authors have received compensation for professional services:

- Professor TJ Shors: Rutgers The State University of New Jersey, National Institutes of Health, National Science Foundation and National Alliance for Research on Schizophrenia and Depression.

- Dr Christina Dalla: Rutgers The State University of New Jersey, National Institutes of Health and National Science Foundation, University of Athens/Greece, European Commission (Marie Curie Outgoing Individual Fellowship).

- Carol Edgecomb BS: Rutgers The State University of New Jersey, National Institutes of Health and National Science Foundation.

- Abigail S Whetstone: Rutgers The State University of New Jersey.

\section{REFERENCES}

Aloisi AM, Bonifazi M (2006). Sex hormones, central nervous system and pain. Horm Behav 50: 1-7.

Alonso SJ, Castellano MA, Afonso D, Rodriguez M (1991). Sex differences in behavioral despair: relationships between behavioral despair and open field activity. Physiol Behav 49: 69-72.

Altemus M (2006). Sex differences in depression and anxiety disorders: potential biological determinants. Horm Behav 50: 534-538.

Arnold AP (2004). Sex chromosomes and brain gender. Nat Rev Neurosci 5: 701-708.

Arnold AP, Breedlove SM (1985). Organizational and activational effects of sex steroids on brain and behavior: a reanalysis. Horm Behav 19: 469-498.

Bangasser DA, Santollo J, Shors TJ (2005). The bed nucleus of the stria terminalis is critically involved in enhancing associative learning after stressful experience. Behav Neurosci 119: 1459-1466.

Bangasser DA, Shors T (2007). The hippocampus is necessary for enhancements and impairments of learning following stressful experience. Nat Neurosci (in press).

Barr CS, Newman TK, Schwandt M, Shannon C, Dvoskin RL, Lindell SG et al (2004a). Sexual dichotomy of an interaction between early adversity and the serotonin transporter gene promoter variant in rhesus macaques. Proc Natl Acad Sci USA 101: 12358-12363.

Barr CS, Newman TK, Shannon C, Parker C, Dvoskin RL, Becker ML et al (2004b). Rearing condition and rh5-HTTLPR interact to influence limbic-hypothalamic-pituitary-adrenal axis response to stress in infant macaques. Biol Psychiatry 55: 733-738.

Barraclough CA, Gorski RA (1961). Evidence that the hypothalamus is responsible for androgen-induced sterility in the female rat. Endocrinology 68: 68-79.

Beatty WW, Beatty PA (1970). Hormonal determinants of sex differences in avoidance behavior and reactivity to electric shock in the rat. J Comp Physiol Psychol 73: 446-455.

Beatty WW, Fessler RG (1977). Gonadectomy and sensitivity to electric shock in the rat. Physiol Behav 19: 1-6.

Breslau N, Davis GC, Andreski P, Peterson EL, Schultz LR (1997). Sex differences in posttraumatic stress disorder. Arch Gen Psychiatry 54: 1044-1048.

Caldarone BJ, George TP, Zachariou V, Picciotto MR (2000). Gender differences in learned helplessness behavior are influenced by genetic background. Pharmacol Biochem Behav 66: 811-817.

Cryan JF, Markou A, Lucki I (2002). Assessing antidepressant activity in rodents: recent developments and future needs. Trends Pharmacol Sci 23: 238-245.

Dalla C, Antoniou K, Drossopoulou G, Xagoraris M, Kokras N, Sfikakis A et al (2005). Chronic mild stress impact: are females more vulnerable? Neuroscience 135: 703-714.

Davies W, Wilkinson LS (2006). It is not all hormones: alternative explanations for sexual differentiation of the brain. Brain Res 1126: $36-45$.

Diaz-Veliz G, Soto V, Dussaubat N, Mora S (1989). Influence of the estrous cycle, ovariectomy and estradiol replacement upon the acquisition of conditioned avoidance responses in rats. Physiol Behav 46: 397-401.

Drossopoulou G, Antoniou K, Kitraki E, Papathanasiou G, Papalexi E, Dalla C et al (2004). Sex differences in behavioral, neurochemical and neuroendocrine effects induced by the Forced Swim Test in rats. Neuroscience 126: 849-857.

Drugan RC, Basile AS, Ha JH, Healy D, Ferland RJ (1997). Analysis of the importance of controllable $v s$ uncontrollable stress on subsequent behavioral and physiological functioning. Brain Res Brain Res Protoc 2: 69-74.

Gupta RR, Sen S, Diepenhorst LL, Rudick CN, Maren S (2001). Estrogen modulates sexually dimorphic contextual fear conditioning and hippocampal long-term potentiation (LTP) in rats(1). Brain Res 888: 356-365. 
Han TM, De Vries GJ (2003). Organizational effects of testosterone, estradiol, and dihydrotestosterone on vasopressin mRNA expression in the bed nucleus of the stria terminalis. J Neurobiol 54: $502-510$.

Heinsbroek RP, Feenstra MG, Boon P, Van Haaren F, Van de Poll NE (1988). Sex differences in passive avoidance depend on the integrity of the central serotonergic system. Pharmacol Biochem Behav 31: 499-503.

Heinsbroek RP, Van Haaren F, Van de Poll NE, Steenbergen HL (1991). Sex differences in the behavioral consequences of inescapable footshocks depend on time since shock. Physiol Behav 49: 1257-1263.

Hodes GE, Shors TJ (2005). Distinctive stress effects on learning during puberty. Horm Behav 48: 163-171.

Holden C (2005). Sex and the suffering brain. Science 308: 1574.

Jenkins JA, Williams P, Kramer GL, Davis LL, Petty F (2001). The influence of gender and the estrous cycle on learned helplessness in the rat. Biol Psychol 58: 147-158.

Joffe H, Cohen LS (1998). Estrogen, serotonin, and mood disturbance: where is the therapeutic bridge? Biol Psychiatry 44: 798-811.

Johnston AL, File SE (1991). Sex differences in animal tests of anxiety. Physiol Behav 49: 245-250.

Kendler KS (1998). Gender differences in the genetic epidemiology of major depression. J Gend Specif Med 1: 28-31.

Kendler KS, Gardner CO, Neale MC, Prescott CA (2001a). Genetic risk factors for major depression in men and women: similar or different heritabilities and same or partly distinct genes? Psychol Med 31: 605-616.

Kendler KS, Thornton LM, Prescott CA (2001b). Gender differences in the rates of exposure to stressful life events and sensitivity to their depressogenic effects. Am J Psychiatry 158: 587-593.

Kessler RC (2003). Epidemiology of women and depression. J Affect Disord 74: 5-13.

Kessler RC, Sonnega A, Bromet E, Hughes M, Nelson CB (1995). Posttraumatic stress disorder in the National Comorbidity Survey. Arch Gen Psychiatry 52: 1048-1060.

Kirk RC, Blampied NM (1985). Activity during inescapable shock and subsequent escape avoidance learning: female and male rats compared. $N Z$ J Psychol 14: 9-14.

Klein LC, Corwin EJ (2002). Seeing the unexpected: how sex differences in stress responses may provide a new perspective on the manifestation of psychiatric disorders. Curr Psychiatry Rep 4: 441-448.

Kornstein SG (1997). Gender differences in depression: implications for treatment. J Clin Psychiatry 58(Suppl 15): 12-18.

Leuner B, Mendolia-Loffredo S, Shors TJ (2004). Males and females respond differently to controllability and antidepressant treatment. Biol Psychiatry 56: 964-970.

Leuner B, Shors TJ (2006). Learning during motherhood: a resistance to stress. Horm Behav 50: 38-51.

Levine S, Broadhurst PL (1963). Genetic and ontogenetic determinants of adult behavior in the rat. J Comp Physiol Psychol 56: 423-428.

Maciejewski PK, Prigerson HG, Mazure CM (2001). Sex differences in event-related risk for major depression. Psychol Med 31: 593-604.

MacLusky NJ, Clark AS, Naftolin F, Goldman-Rakic PS (1987). Estrogen formation in the mammalian brain: possible role of aromatase in sexual differentiation of the hippocampus and neocortex. Steroids 50: 459-474.

MacLusky NJ, Naftolin F (1981). Sexual differentiation of the central nervous system. Science 211: 1294-1302.

Maier SF (1984). Learned helplessness and animal models of depression. Prog Neuropsychopharmacol Biol Psychiatry 8: $435-446$.
Maier SF, Watkins LR (2005). Stressor controllability and learned helplessness: the roles of the dorsal raphe nucleus, serotonin, and corticotropin-releasing factor. Neurosci Biobehav Rev 29: 829-841.

Maren S, De Oca B, Fanselow MS (1994). Sex differences in hippocampal long-term potentiation (LTP) and Pavlovian fear conditioning in rats: positive correlation between LTP and contextual learning. Brain Res 661: 25-34.

McCarthy MM, Konkle AT (2005). When is a sex difference not a sex difference? Front Neuroendocrinol 26: 85-102.

Meagher D, Murray D (1997). Depression. Lancet 349(Suppl 1): sI17-sI20.

Miller WR, Seligman ME (1975). Depression and learned helplessness in man. J Abnorm Psychol 84: 228-238.

Morris JA, Jordan CL, Breedlove SM (2004). Sexual differentiation of the vertebrate nervous system. Nat Neurosci 7: 1034-1039.

Nemeroff CB, Bremner JD, Foa EB, Mayberg HS, North CS, Stein MB (2006). Posttraumatic stress disorder: a state-of-the-science review. J Psychiatr Res 40: 1-21.

Nestler EJ, Gould E, Manji H, Buncan M, Duman RS, Greshenfeld HK et al (2002). Preclinical models: status of basic research in depression. Biol Psychiatry 52: 503-528.

Overmier JB, Seligman ME (1967). Effects of inescapable shock upon subsequent escape and avoidance responding. J Comp Physiol Psychol 63: 28-33.

Palanza P (2001). Animal models of anxiety and depression: how are females different? Neurosci Biobehav Rev 25: 219-233.

Romero MT, Cooper ML, Komisaruk BR, Bodnar RJ (1988). Gender-specific and gonadectomy-specific effects upon swim analgesia: role of steroid replacement therapy. Physiol Behav 44: 257-265.

Romero MT, Kepler KL, Cooper ML, Komisaruk BR, Bodnar RJ (1987). Modulation of gender-specific effects upon swim analgesia in gonadectomized rats. Physiol Behav 40: 39-45.

Roof RL (1993). Neonatal exogenous testosterone modifies sex difference in radial arm and Morris water maze performance in prepubescent and adult rats. Behav Brain Res 53: 1-10.

Roof RL, Havens MD (1992). Testosterone improves maze performance and induces development of a male hippocampus in females. Brain Res 572: 310-313.

Roselli CE, Klosterman SA (1998). Sexual differentiation of aromatase activity in the rat brain: effects of perinatal steroid exposure. Endocrinology 139: 3193-3201.

Rubinow DR, Schmidt PJ, Roca CA (1998). Estrogen-serotonin interactions: implications for affective regulation. Biol Psychiatry 44: $839-850$.

Scouten CW, Groteleuschen LK, Beatty WW (1975). Androgens and the organization of sex differences in active avoidance behavior in the rat. J Comp Physiol Psychol 88: 264-270.

Seale JV, Wood SA, Atkinson HC, Harbuz MS, Lightman SL (2005). Postnatal masculinization alters the HPA axis phenotype in the adult female rat. $J$ Physiol 563: 265-274.

Seligman ME, Beagley G (1975). Learned helplessness in the rat. J Comp Physiol Psychol 88: 534-541.

Seligman ME, Maier SF (1967). Failure to escape traumatic shock. J Exp Psychol 74: 1-9.

Setnik B, de Souza FG, d'Almeida V, Nobrega JN (2004). Increased homocysteine levels associated with sex and stress in the learned helplessness model of depression. Pharmacol Biochem Behav 77: 155-161.

Sfikakis A, Spyraki C, Sitaras N, Varonos D (1978). Implication of the estrous cycle on conditioned avoidance behavior in the rat. Physiol Behav 21: 441-446.

Sherrill JT, Anderson B, Frank E, Reynolds III CF, Tu XM, Patterson D et al (1997). Is life stress more likely to provoke depressive episodes in women than in men? Depress Anxiety 6: 95-105. 
Shors TJ (1998). Stress and sex effects on associative learning: for better or for worse. Neuroscientist 4: 353-364.

Shors TJ, Mathew J, Sisti HM, Edgecomb C, Beckoff S, Dalla C (2007). Neurogenesis and helplessness are mediated by controllability in males but not in females. Biol Psychiatry 6215: 487-495.

Shors TJ (2006). Stressful experience and learning across the lifespan. Annu Rev Psychol 57: 55-85.

Shors TJ, Miesegeas G (2002). Testosterone in utero and at birth dictates how stressful experience will affect learning in adulthood. Proc Natl Acad Sci USA 99: 13955-13960.

Shors TJ, Seib TB, Levine S, Thompson RF (1989). Inescapable $v s$ escapable shock modulates long-term potentiation in the rat hippocampus. Science 244: 224-226.

Sisk CL, Zehr JL (2005). Pubertal hormones organize the adolescent brain and behavior. Front Neuroendocrinol 26: 163-174.

Sjoberg RL, Nilsson KW, Nordquist N, Ohrvik J, Leppert J, Lindstrom L et al (2006). Development of depression: sex and the interaction between environment and a promoter polymorphism of the serotonin transporter gene. Int J Neuropsychopharmacol 9: 443-449.

Somers JM, Goldner EM, Waraich P, Hsu L (2006). Prevalence and incidence studies of anxiety disorders: a systematic review of the literature. Can J Psychiatry 51: 100-113.

Steenbergen HL, Heinsbroek RP, Van Hest A, Van de Poll NE (1990). Sex-dependent effects of inescapable shock administration on shuttlebox-escape performance and elevated plus-maze behavior. Physiol Behav 48: 571-576.

Stein MB, Jang KL, Taylor S, Vernon PA, Livesley WJ (2002). Genetic and environmental influences on trauma exposure and posttraumatic stress disorder symptoms: a twin study. Am J Psychiatry 159: 1675-1681.

Steiner M, Allgulander C, Ravindran A, Kosar H, Burt T, Austin C (2005). Gender differences in clinical presentation and response to sertraline treatment of generalized anxiety disorder. Hum Psychopharmacol 20: 3-13.

Steiner M, Dunn E, Born L (2003). Hormones and mood: from menarche to menopause and beyond. J Affect Disord 74: 67-83.

Toufexis D, Davis C, Hammond A, Davis M (2005). Sex differences in hormonal modulation of anxiety measured with light- enhanced startle: possible role for arginine vasopressin in the male. J Neurosci 25: 9010-9016.

Toufexis DJ, Myers KM, Davis M (2006). The effect of gonadal hormones and gender on anxiety and emotional learning. Horm Behav 50: 539-549.

van Haaren F, van de Poll NE (1984a). The effect of a choice alternative on sex differences in passive avoidance behavior. Physiol Behav 32: 211-215.

van Haaren F, van de Poll NE (1984b). The number of pre-shock trials affects sex differences in passive avoidance behavior. Physiol Behav 33: 269-272.

Van Oyen HG, Van de Poll NE, De Bruin JP (1979). Sex, age and shock-intensity as factors in passive avoidance. Physiol Behav 23: 915-918.

van Oyen HG, van de Poll NE, De Bruin JP (1980). Effects of retention interval and gonadectomy on sex differences in passive avoidance behavior. Physiol Behav 25: 859-862.

Vendruscolo LF, Pamplona FA, Takahashi RN (2004). Strain and sex differences in the expression of nociceptive behavior and stress-induced analgesia in rats. Brain Res 1030: 277-283.

Vollmayr B, Henn FA (2001). Learned helplessness in the rat: improvements in validity and reliability. Brain Res Brain Res Protoc 8: 1-7.

Weiss LA, Abney M, Cook Jr EH, Ober C (2005). Sex-specific genetic architecture of whole blood serotonin levels. Am J Hum Genet 76: 33-41.

Williams CL, Barnett AM, Meck WH (1990). Organizational effects of early gonadal secretions on sexual differentiation in spatial memory. Behav Neurosci 104: 84-97.

Williams CL, Meck WH (1991). The organizational effects of gonadal steroids on sexually dimorphic spatial ability. Psychoneuroendocrinology 16: 155-176.

Willner P (1986). Validation criteria for animal models of human mental disorders: learned helplessness as a paradigm case. Prog Neuropsychopharmacol Biol Psychiatry 10: 677-690.

Willner P (1995). Animal models of depression: validity and applications. Adv Biochem Psychopharmacol 49: 19-41.

Wood GE, Shors TJ (1998). Stress facilitates classical conditioning in males, but impairs classical conditioning in females through activational effects of ovarian hormones. Proc Natl Acad Sci USA 95: 4066-4071. 